\title{
Resenha do livro: Espaço de formação do psicólogo no Brasil-20 anos da Clínica Psicológica Alvino Augusto de Sá, de Berenice Carpigiani e Sandra Ribeiro de Almeida Lopes (Orgs.)
}

Armando Rocha Junior' Universidade Guarulhos (Guarulhos) e Universidade de Taubaté (Taubaté) - SP - Brasil

Na ocasião em que o curso de Psicologia da Universidade Presbiteriana Mackenzie (UPM) faz 25 anos de sua formação e a Clínica Psicológica completa 20 anos, o lançamento o livro Espaço de formação do psicólogo no Brasil - 20 anos da Clínica Psicológica Alvino Augusto de Sá (Carpigiani \& Lopes, 2014) representa um marco significativo no cenário da formação dos psicólogos no Brasil. Tendo sido o organizador e primeiro coordenador do curso, a oportunidade de resenhá-lo e recordar os fatos relacionados a esse momento permite compartilhar com a comunidade científica um fazer que busca integrar o tripé ensino, pesquisa e extensão. O livro foi organizado em nove capítulos escritos por diferentes professores e supervisores que fazem parte de diferentes momentos da história da Clínica Psicológica da UPM e da Psicologia no Brasil.

No Capítulo 1, a Profa. Berenice Carpigiani discorre sobre a decisão da UPM, sob orientação da Magnífica Reitora Dra. Aurora Albanese, de implantar o curso de Psicologia, bem como formar sua primeira equipe gestora, que permaneceu por cerca de 11 anos à frente dele. Nesse período, o curso foi oficialmente reconhecido pelo Ministério da Educação e do Desporto, e a Clínica Psicológica, hoje Clínica Alvino Augusto de Sá, foi implantada. A autora faz referência ao crescimento do curso e à consequente demanda por atendimento psicológico, principalmente, pelas pessoas residentes no entorno do campus universitário, visto que a clínica de então estava instalada em um dos prédios da universidade. Com o crescimento da clientela, a coordenação do curso de Psicologia, em consonância com a coordenação da Clínica, fez gestões junto à UPM para que a clínica fosse transferida para fora do campus, oferecendo maior privacidade aos seus usuários. Assim foi feito, e a nova clínica passou a funcionar em um espaço muito maior, agora na conhecida e histórica Rua Maria Antonia. Em 1998, o curso de Psicologia passou a ter status de faculdade, e o seu primeiro diretor, professor Armando Rocha Junior, foi empossado juntamente com os seus quatro chefes de departamento: professores Carlos Roberto Dias lema (Psicologia Organizacional), Paulo Francisco de Castro (Psicologia Clínica), Jumara Sílvia Van De Velde (Psicologia Escolar) e Sueli G. Carvalho (Psicologia Geral e Experimental). Em 2001, teve início nova gestão administrativa da Faculdade de Psicologia, cujo foco foi adaptar o currículo já existente às

${ }^{1}$ Endereço para correspondência: Armando Rocha Junior, Universidade Guarulhos, Centro de Ciências Biológicas e da Saúde, Praça Tereza Cristina, 1, Centro - Guarulhos - SP - Brasil. CEP: 07023-070. E-mail: armandopsico@ uol.com.br. 
novas diretrizes curriculares e determinações do Ministério da Educação e Cultura. De acordo com a autora do capítulo, essa fase, a partir de 2001, foi turbulenta e de mudanças nas diversas chefias. Em 2006, foi efetivada a reestruturação acadêmico-administrativa da UPM, operacionalizando a junção de faculdades em centros, voltando a Faculdade de Psicologia a ser denominada curso de Psicologia e a integrar o Centro de Ciências Biológicas e da Saúde. Em 2008, a Clínica Psicológica assumiu seu novo endereço: Rua Piauí, 181.

No Capítulo 2, segundo as autoras, a entrada do paciente na Clínica Psicológica da UPM, quer seja ele adulto, adolescente ou criança, sempre acontece por intermédio da entrevista de triagem. Essa forma de acolhimento é realizada pelos alunos do oitavo semestre do curso de Psicologia. Para muitos desses alunos, trata-se da primeira grande experiência clínica em que terão a oportunidade de pôr em prática toda a teoria que aprenderam até então, como: desenvolvimento humano, psicopatologia, entre outras. Segundo as autoras, a entrevista de triagem é a porta de entrada dos clientes para conseguir atingir seu objetivo principal, ou seja, o melhor encaminhamento para sua queixa. Após a triagem, a grande maioria dos casos é encaminhada para o atendimento em psicodiagnóstico, salvo se outras necessidades terapêuticas se apresentarem imperiosas. No psicodiagnóstico, o cliente encontrará estagiários preparados previamente na disciplina teórica do mesmo nome, bem como no início do curso em disciplinas voltadas à avaliação psicológica (testes psicológicos), sempre visando à compreensão global daquele que está entregando sua saúde mental aos cuidados da clínica psicológica.

No Capítulo 3, as autoras afirmam que há 20 anos, quando os primeiros profissionais foram contratados para atuar como supervisores na Clínica Psicológica da UPM, já o foram com base na nova realidade para formação de psicólogos brasileiros, inspirada em Ryad Simon. Era a psicoterapia de curto prazo que também coincidia com a breve permanência do estagiário em sua função de psicoterapeuta na clínica. Assim, foram implantados os estágios obrigatórios em Psicoterapia Breve de Adulto (PBA) e Psicoterapia Breve Infantil $(\mathrm{PBI})$, e este último subentendia um trabalho paralelo de orientação de pais.

No Capítulo 4, as autoras destacam que a Clínica-Escola da UPM, depois de muita discussão entre seus supervisores, implantou o atendimento específico para adolescentes. Até então, os jovens entre 11 e 13 anos de idade, aproximadamente, ora eram atendidos em Psicoterapia Breve Infantil, ora em Psicoterapia Breve de Adultos. Seguindo os preceitos éticos, os pais ou responsáveis pelos adolescentes precisam autorizar a realização dos atendimentos, bem como, em paralelo, podem receber ou não atendimentos também. Não é raro que haja encaminhamentos externos para os responsáveis pelos adolescentes em atendimento. Nesse capítulo, fica muito claro que os pais ou responsáveis pelos adolescentes são sempre convidados firmemente a aliar-se ao processo de tratamento destes.

No Capítulo 5, os autores enfatizam que, desde 1994, quando foi inaugurada a Clínica-Escola de Psicologia da UPM, sua proposta sempre foi a de bem atender a população, de acordo com a realidade brasileira. Ao longo desses 20 anos, a direção e o corpo docente mantêm o propósito de uma formação em Psicologia comprometida com a sociedade. 
A Clínica não só ajuda na formação dos alunos, mas também presta serviços à comunidade e realiza pesquisas. De 1994 a 2002, foram oferecidas duas modalidades de estágios principais em Psicologia Clínica: Psicoterapia Breve Infantil e Psicoterapia Breve de Adultos, ambas na abordagem psicodinâmica. Segundo os autores, a partir de 2002, em função de mudanças no projeto pedagógico do curso de Psicologia, passaram a ser oferecidas outras opções de estágios em diferentes perspectivas teóricas, entre as quais se destacam Psicoterapia Comportamental e Gestalt-terapia.

No Capítulo 6, as autoras relatam que a Clínica Psicológica do curso de Psicologia da UPM tem como objetivo complementar a formação do acadêmico, oferecendo-lhe a experiência prática, aliando a teoria, a ética e o raciocínio clínico, no momento em que atua dentro do seu estágio. Este pode ser nas áreas clínica ou institucional. O estágio em Psicologia Clínica permite a utilização de instrumentos e técnicas de avaliação e intervenção clínica em diferentes enfoques teóricos, sempre considerando o ambiente e a saúde integral do indivíduo, com a finalidade de melhorar sua qualidade de vida, que é seu direito como cidadão. Para capacitar o aluno quintanista do curso de Psicologia a atuar em equipes inter e multidisciplinares e ou transdisciplinares, foi organizado o estágio em Psicologia da Saúde, que enfatiza o caráter educativo da assistência. Ainda nesse capítulo, pode-se apreender a importância das supervisões na formação acadêmica do psicólogo, pois é nesse momento particular que as características e vulnerabilidades dos alunos em formação podem vir à tona e tornar a experiência de aprendizagem bastante rica, mas também muito mais complexa.

No Capítulo 7, as autoras, antes de maiores considerações, chamam atenção para o dinamismo do ambiente clínico e da relevância de se prestar atenção às necessidades da população. Tratam também das técnicas consagradas que ajudam verdadeiramente a diversificar as áreas de atuação no campo da Psicologia, dentro do referencial clínico, incorporadas à rotina das clínicas-escola. Ainda de acordo com as autoras, o trabalho psicológico precisa estar em sintonia com as técnicas psicológicas e os contextos nos quais estas são empregadas. Como bem afirmou Sant'Anna (2005, citado por Carpigiani \& Lopes, 2014), faz-se necessário deixar claro o modo de pensar oriundo da ciência psicológica e a forma como esta pode se relacionar nos mais variados contextos, operacionalizando teorias e valorizando o conhecimento teórico com diferentes possibilidades de entendimento. Esse capítulo deixa claro que o estagiário, diante de seu cliente, antes de mais nada, precisa primar em interpretar corretamente a sua realidade, para que todos os seus passos sejam dados dentro de uma margem de acerto o mais próxima possível do correto e condizente com o real. Para que o dinamismo citado no início desse capítulo aconteça de fato, as pesquisas na área clínica são de fundamental importância. É uma necessidade intrínseca às atividades clínicas, contudo ainda sem plenas condições de se tornarem realidade, conforme apontam as autoras, esperançosas sobre mudanças.

No Capítulo 8, as autoras mostram a importância da municipalização da saúde e do atendimento em rede, observando as necessidades de cada região. Destacam que a formação de especialistas deve contemplar o conhecimento e a experiência da atuação nas 
diversas unidades de saúde, da prevenção à reabilitação. No que se refere aos alunos de Psicologia, estes devem ser preparados para atender desde nos tradicionais consultórios até em equipes interdisciplinares, abrangendo um número expressivo de pessoas da população, levando a Psicologia aos mais necessitados financeiramente falando. Dessa forma, como afirmam as autoras, o domínio da atuação interdisciplinar deve estar presente no psicólogo recém-formado ou em fase final de formação.

Outro aspecto importante destacado pelas autoras diz respeito às parcerias entre a Clínica-Escola, área de Psicologia da Saúde e diversos equipamentos de saúde, como: hospitais geral e psiquiátrico, comunidade terapêutica, Centro de Atenção Psicossocial (Caps), unidade básica de saúde (UBS), centros de convivências, entre outros. Tais parcerias são importantes, pois asseguram a proximidade do estagiário da realidade e levam os novos conceitos aprendidos na universidade às instituições públicas, resultando em um melhor atendimento ao público em geral.

No capítulo 9, os autores mostram a preocupação em afinar a filosofia da Clínica-Escola Alvino Augusto de Sá com o dinamismo da realidade social brasileira. Tal preocupação parece uma constante no curso de Psicologia da UPM, haja vista a menção desse aspecto em capítulos anteriores. Os autores deixam claro que conhecem afirmações de que os psicólogos possuem grandes dificuldades para desapegar-se das referências teóricas e técnicas que historicamente os identificavam profissionalmente, mas também destacam que, a partir de 2002, as novas Diretrizes Curriculares Nacionais para os cursos de Psicologia, deram um impulso para a formação generalista, preparando o profissional para uma leitura crítica da realidade e para o atendimento de demandas sociais amplas, obrigando-o a se desencastelar. Por tudo o que foi possível observar, desde o início do curso de Psicologia da UPM até os dias atuais, o projeto pedagógico contempla mais o geral do que o particular, portanto trata-se de um projeto em consonância com a sociedade e com os direitos desta.

Ter resenhado o presente livro foi, antes de mais nada, a oportunidade de relembrar algumas situações vividas e principalmente inúmeras pessoas que lutaram ao nosso lado para que o curso de Psicologia da UPM se tornasse realidade. Assim, esta obra é plenamente indicada para todos aqueles que se interessam pelos bastidores da formação do psicólogo e pelas abordagens que podem permear a base da estruturação de um bom profissional da Psicologia.

\section{Referência}

Carpigiani, B., \& Lopes, S. R. A. (Orgs.). (2014). Espaço de formação do psicólogo no Brasil - 20 anos da Clínica Psicológica Alvino Augusto de Sá. São Paulo: Editora Mackenzie. 